\title{
PENERAPAN DEKONVOLUSI SPIKING DAN DEKONVOLUSI PREDIKTIF PADA DATA SEISMIK MULTICHANNEL 2D DI LAUT FLORES
}

\section{APPLICATION OF SPIKING DECONVOLUTION AND PREDICTIVE DECONVOLUTION ON 2D SEISMIC MULTICHANNEL DATA IN FLORES SEA}

\author{
Alfrida Romauli ${ }^{1}$, Henry M. Manik ${ }^{2}$, Subarsyah ${ }^{3}$ \\ ${ }^{1}$ Program Studi Ilmu dan Teknologi Kelautan, Fakultas Perikanan dan Ilmu Kelautan \\ ${ }^{2}$ Departemen Ilmu dan Teknologi Kelautan, \\ Fakultas Perikanan dan Ilmu Kelautan, Institut Pertanian Bogor \\ ${ }^{3}$ Pusat Penelitian dan Pengembangan Geologi Kelautan (PPPGL), Bandung \\ Korespondensi: henrymanik@gmail.com
}

\begin{abstract}
The use of seismic reflection in ocean has become an activity that is often performed with a variety of purposes, to map the subsurface. The basic objective of seismic data processing is to convert the recorded information from the field into data that can be interpreted. One goal of seismic data processing is to eliminate or reduce the noise of reverberation and multiples as well as enhance the signal to noise ratio. This study uses data line 16 in the Flores Sea extension SEG-Y. The research was conducted in February- March 2015, in marine geology research and development, Bandung. The method used in this study is spiking deconvolution and predictive deconvolution. This study was conducted to analyze the differences in seismic migration poststack results using predictive deconvolution and spiking deconvolution. The results obtained are both deconvolution can increase the signal to noise ratio in the data. Migration using both spiking and predictive deconvolution results are not much different due to the influence of irregular signature tail because of synchronization airgun less effective.
\end{abstract}

Keyword: deconvolution, predictive deconvolution, signal to noise ratio, spiking deconvolution

\begin{abstract}
ABSTRAK
Tujuan dasar dari pengolahan data seismik yaitu untuk mengkonversikan informasi yang terekam dari lapang menjadi data yang dapat diinterpretasikan. Salah satu tujuan prosesing data seismik adalah untuk menghilangkan atau mengurangi noise dari reverberasi dan multiples serta mempertinggi rasio sinyal terhadap noise. Penelitian ini menggunakan data lintasan 16 di Laut Flores yang berekstensi SEG-Y. Penelitian dilaksanakan pada bulan FebruariMaret 2015 di Pusat Penelitian dan Pengembangan Geologi Kelautan (PPPGL), Bandung. Metode yang digunakan dalam penelitian ini adalah dekonvolusi spiking dan dekonvolusi prediktif. Penelitian ini dilakukan untuk menganalisis perbedaan penampang seismik hasil poststack migration dengan menggunakan dekonvolusi prediktif dan dekonvolusi spiking. Hasil yang didapat yaitu kedua dekonvolusi dapat meningkatkan rasio sinyal terhadap noise pada data namun dekonvolusi prediktif dapat memberikan hasil lebih baik dalam meningkatkan rasio sinyal terhadap noise. Penampang migrasi dengan menggunakan dekonvolusi baik spiking maupun prediktif memberikan hasil yang tidak jauh berbeda, namun multiple tidak dapat dihilangkan dengan menggunakan dekonvolusi prediktif disebabkan karena pengaruh ekor signature yang tidak teratur akibat sinkronisasi airgun kurang efektif.
\end{abstract}

Kata kunci: dekonvolusi, dekonvolusi prediktif, dekonvolusi spiking, signal to noise ratio 


\section{PENDAHULUAN}

\section{Latar belakang}

Penggunaan seismik refleksi di laut telah menjadi suatu kegiatan yang sering dilakukan dengan berbagai tujuan, yaitu untuk memetakan lapisan bawah permukaan. Data seismik dari proses geofisika lapangan memiliki karakteristik data dan gangguan (noise) yang tidak dapat dipisahkan. Noise yang terkandung dalam rekaman seismik memberikan tampilan efek lapisan semu dan rekaman data yang kurang baik. Padahal data seismik yang ideal seharusnya menampilkan gelombang refleksi yang dapat memberikan informasi penampang seismik bawah permukaan laut. Tanpa adanya proses lanjutan yang memadai, data seismik tidak akan mendapatkan penggambaran bawah permukaan yang sesungguhnya. Peran metode seismik diperlukan sebagai usaha dalam perolehan refleksi bawah permukaan yang sebenarnya. Penampang seismik yang jelas dan beresolusi tinggi dapat diperoleh dengan pengolahan data seismik. Salah satu tujuan pemrosesan data seismik adalah untuk mengurangi noise dan multiples (Egbai dan Ekpekpo 2012) sehingga mempertinggi signal to noise ratio (SNR). Kualitas rekaman seismik dapat dinilai dari rasio sinyal refleksi terhadap sinyal gangguan. Pengolahan data seismik dilakukan untuk meningkatkan sinyal dan melemahkan sinyal gangguan (noise) sehingga refleksi data seismik yang diperlukan meningkat dan gangguan dapat ditekan serta memperbaiki resolusi vertikal pada trace seismik (Kearey et al. 2002).

Peningkatan resolusi rekaman seismik dapat dilakukan dengan menerapkan berbagai macam metode. Peningkatan resolusi dapat dilakukan salah satunya dengan mengaplikasikan dekonvolusi pada rekaman seismik. Dekonvolusi merupakan suatu proses inverse dari konvolusi yang menghilangkan efek filter bumi pada gelombang sumber. Selain itu dekonvolusi dapat menghilangkan noise dan multiple yang terkandung dalam rekaman seismik.

Metode dekonvolusi yang dipilih untuk meningkatkan resolusi penampang seismik pada penelitian ini adalah dengan dekonvolusi prediktif dan dekonvolusi spiking. Dekonvolusi prediktif merupakan proses mengaplikasikan informasi dari awal trace seismik untuk memprediksi sistem noise dan multiple. Sedangkan dekonvolusi spiking mengubah wavelet seismik menjadi spike. Kedua metode ini diharapkan dapat menghasilkan penampang seismik yang lebih representatif dengan berkurangnya kehadiran noise yang mengganggu interpretasi data serta mampu meningkatkan resolusi penampang seismik. Penelitian ini bertujuan untuk membandingkan hasil penampang refleksi seismik dengan penerapan dekonvolusi prediktif dan dekonvolusi spiking serta menentukan jenis dekonvolusi yang mampu meningkatkan kualitas signal to noise ratio (snr) pada data seismik laut di perairan Flores.

\section{METODE PENELITIAN}

Lokasi penelitian dan pengolahan data dilakukan di Laboratorium Seismik Pusat Penelitian dan Pengembangan Geologi Kelautan (PPPGL), Kementrian Energi dan Sumber Daya Mineral (ESDM), Bandung, Jawa Barat. Lokasi penelitian berada di Laut Flores. Akuisisi data dilakukan oleh P3GL pada Mei 2012. Lintasan yang digunakan pada penelitian ini adalah Lintasan 16 yang berekstensi SEG-Y. Peta lintasan survey dan batimetri pada perairan Flores dapat dilihat pada Gambar 1. Peta batimetri diperoleh melalui citra satelit SRTM NASA pada tahun 2010. Pengolahan data pada penelitian ini menggunakan perangkat keras bersistem operasi Linux dan perangkat lunak Promax 2D Version 5000.0.0 CLandmark Graphics Corporation 1989-2008. All Rights Reserved, dan ArcGIS 10.

Tahapan pengolahan data yang dilakukan antara lain yaitu tahap prapemrosesan dan pemrosesan. Tahapan prapemrosesan terdiri dari penugasan geometry, editing, dan dekonvolusi. Tahap pemrosesan terdiri dari analisis kecepatan, koreksi NMO, penumpukan, dan migrasi. Gambar 2 merupakan alur pengolahan data seismik penelitian. Tahapan pengolahan data yaitu sebagai berikut:

1. Input SEG-Y merupakan tahap pemasukan data Line FLRS-16 yang bertipe SEG-Y.

2. Geometri merupakan tahap pengkondisian data lapang dengan mencocokkan koordinat shot dan receiver sesuai dengan parameter pada saat akuisisi data agar data yang diolah sesuai dengan geometri yang ada di lapang. Parameter akuisisi data ditampilkan pada Tabel 1.

3. Tahapan editing dan picking merupakan tahapan picking first 
break untuk muting dan untuk pembuatan gate autokorelasi. Selain itu tahapan picking pada first break dan batas bawah refleksi untuk membuat deconvolution gate sebagai batas interval waktu sinyal yang akan diproses.

4. Pada tahapan preprocessing dilakukan proses True Amplitude Recovery (TAR), bandpass filter dan dekonvolusi. Tahapan penerapan TAR yaitu untuk mengembalikan amplitudo yang teratenuasi. NilaiTAR diperoleh melalui parameter test yaitu sebesar $-1 \mathrm{~dB} /$ sec. Bandpass filter yang digunakan yaitu 10-15 Hz, 70-80 Hz. Pada tahapan dekonvolusi dilakukan dua jenis dekonvolusi yaitu dekonvolusi spiking dan dekonvolusi prediktif dengan operator length $190 \mathrm{~ms}$ dan prediction distance $30 \mathrm{~ms}$. Parameter dekonvolusi diperoleh melalui hasil autokorelasi dan parameter test.
5. Pemrosesan data

Pada tahapan ini dilakukan analisis kecepatan dan koreksi NMO,stacking dan migrasi.

a. Proses analisa kecepatan dilakukan untuk mendapatkan nilai kecepatan gelombang yang dianggap sebagai gelombang primer. Metode yang digunakan untuk analisa kecepatan adalah metode semblance. Picking kecepatan dilakukan pada semblance panel. Koreksi NMO dilakukan untuk meluruskan reflektor dan dilakukan pada tahapan picking kecepatan.

b. Stacking dan migrasi. Stacking untuk penjumlahan trace menjadi CDP sedangkan migrasi mengembalikan posisi reflektor ke posisi yang sebenarnya. Proses migrasi menggunakan migrasi Kirchhoff Time Migration.

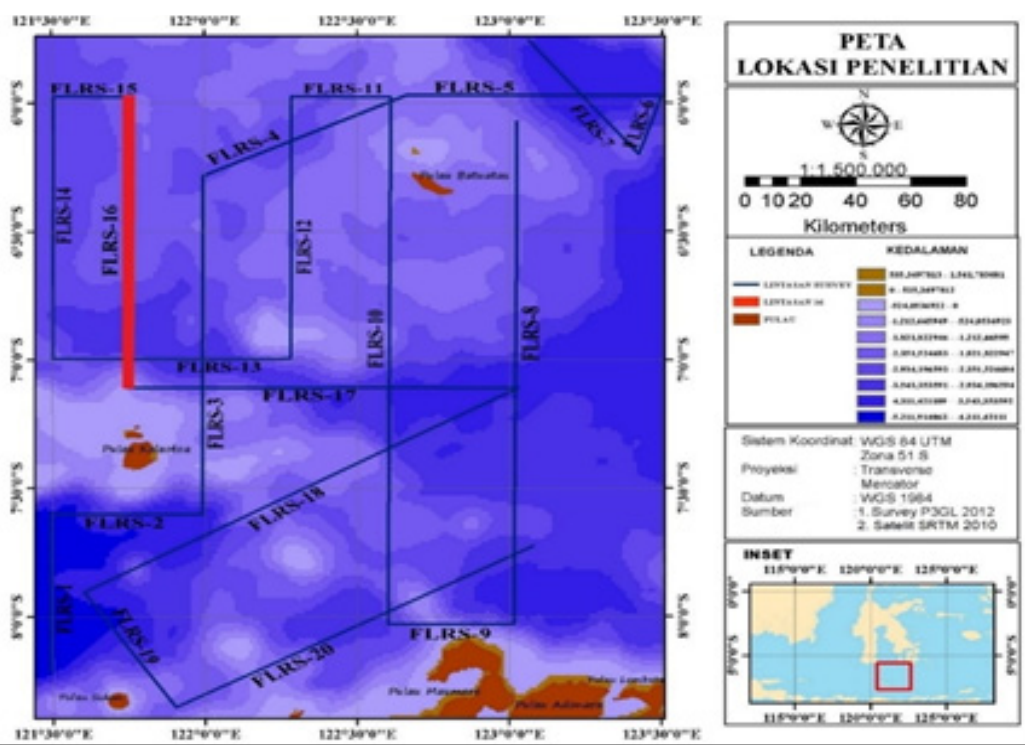

Gambar 1. Peta lintasan survei pada citra topografi di Laut Flores. Lintasan survei ditandai dengan garis hitam dan lintasan 16 ditandai dengan garis merah 


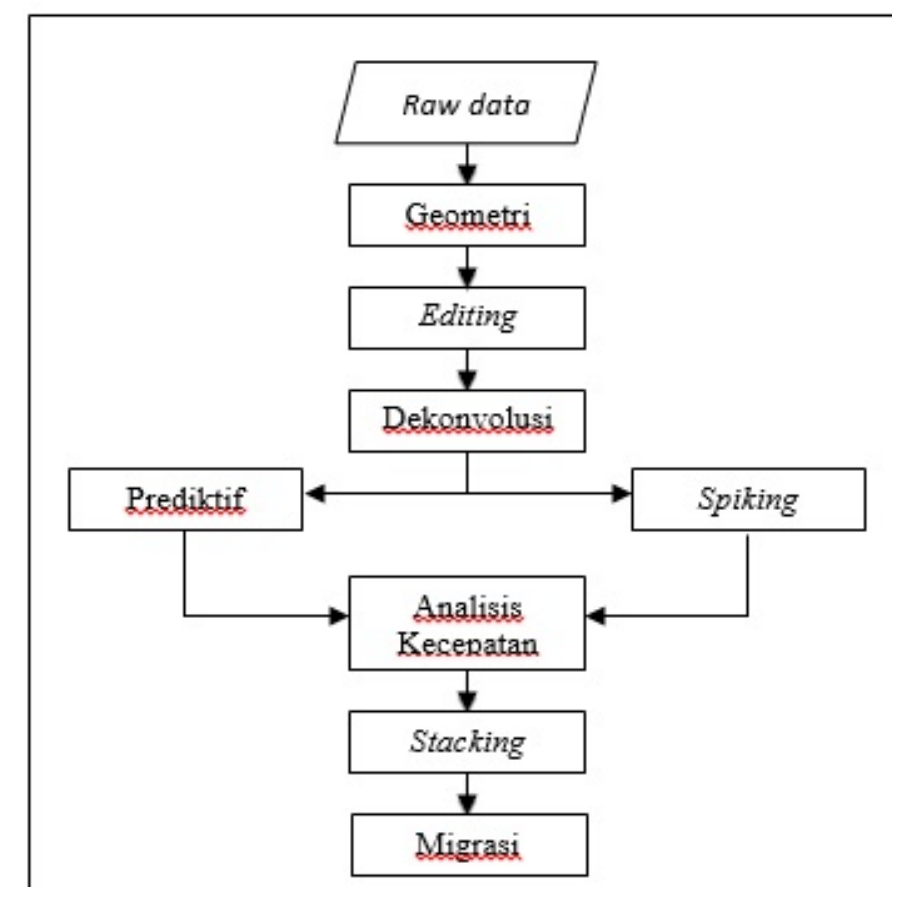

Gambar 2. Alur pengolahan data seismik pada software ProMax 2D

Tabel 1. Parameter akusisi lintasan 16

\begin{tabular}{lc}
\hline Parameter akusisi & Nilai \\
\hline Shot Interval & 37.50 meter \\
Channel Interval & 12.50 meter \\
Near/Minimum Offset & 96 meter \\
Nominal Source Depth & 4 meter \\
Nominal Receiver Depth & 7 meter \\
Number of Shots & 3.230 \\
Sail Line Azimuth & $180^{\circ}$ \\
\hline
\end{tabular}

\section{HASIL DAN PEMBAHASAN}

Hasil penerapan dekonvolusi ditunjukkan melalui wiggle trace, analisis spektral dan penampang hasil migrasi.

\section{Wiggle trace}

Gambar 3 merupakan wiggle trace output geometri, Gambar 4 merupakan wiggle trace setelah penerapan dekonvolusi spiking sedangkan Gambar 5 merupakan gambar wiggle trace setelah penerapan dekonvolusi prediktif. Hasil perekaman seismik refleksi akan selalu mengandung noise. Pada tampilan wiggle trace pada Gambar 3 menampilkan noise acak yang bercampur dengan sinyal refleksi sehingga akan menurunkan kualitas rekaman seismik. Noise juga terlihat setelah peristiwa refleksi yang memiliki amplitudo yang tinggi dan bentuknya tidak koheren. Selain itu trace menunjukkan adanya channel yang tidak merefleksikan amplitudo gelombang seismik yang ditandai kotak berwarna biru yaitu pada recording channel nomor 54 . Peristiwa ini merupakan noise yang terjadi karena kerusakan kanal saat akuisisi sehingga disebut noise instrumen (Yilmaz 1987).

Wiggle trace dengan penerapan dekonvolusi jika dibandingkan dengan wiggle trace geometri menunjukkan hasil yang lebih bersih dari noise. Jika kedua wiggle trace dekonvolusi pediktif dan dekonvolusi spiking dibandingkan maka terlihat bahwa 
wiggle trace dengan penerapan dekonvolusi prediktif (Gambar 5) menampilkan trace yang lebih bersih dari noise dibandingkan dengan wiggle trace pada dekonvolusi spiking (Gambar 4). Perbedaan keduanya terlihat jelas pada first break yang lebih baik pada dekonvolusi prediktif. Hasil dekonvolusi prediktif menunjukkan wiggle trace yang lebih bersih dari noise.

\section{Analisis spektral dekonvolusi}

Hasil analisis spektral menunjukkan perubahan energi wavelet. Secara keseluruhan spektrum amplitudo memperlihatkan amplitudo noise dapat dilemahkan dan amplitudo sinyal dapat dikuatkan. Penguatan amplitudo sinyal menunjukkan bahwa wavelet telah dipersingkat sehingga menghasilkan resolusi yang lebih baik pada penampang seismik (Yilmaz 2001).

Pada spektrum amplitudo dekonvolusi spiking (Gambar 6) jika dibandingkan dengan spektrum amplitudo dekonvolusi prediktif pada Gambar 7 menunjukkan nilai power yang mengalami peningkatan. Pada dekonvolusi spiking nilai power sinyal yaitu sebesar $-10 \mathrm{~dB}$, sementara dengan penerapan dekonvolusi prediktif yaitu sebesar -1 dB. Peningkatan energi trace setelah dekonvolusi merupakan salah satu keberhasilan dekonvolusi yaitu wavelet mengalami pemendekan.

Spektrum fasa pada Gambar 6 dan Gambar 7 memperlihatkan spektrum minimum pada domain frekuensi (minimum phase) yaitu nilai fasa tertinggi merupakan fasa sinyal dan nilai fasa rendah merupakan fasa noise. Kisaran nilai fasa pada dekonvolusi spiking yaitu antara -70 radian hingga 70 radian. Dengan penerapan dekonvolusi prediktif kisaran nilai fasa yaitu -85 radian hingga 65 radian. Sementara pada bagian akhir fasa pada dekonvolusi prediktif yaitu berada pada kisaran 10 radian hingga -35 radian. Dekonvolusi spiking yang memiliki kisaran fasa 20 radian hingga -20 radian. Kisaran nilai fasa akhir terkecil menggambarkan keefektifan dekonvolusi dalam menekan efek noise. Dekonvolusi spiking memiliki kisaran fasa akhir yang lebih kecil dibandingkan dengan dekonvolusi prediktif. Hal ini tidak sesuai dengan teori dalam Zhu dan Wang (2013) yang menyatakan bahwa dekonvolusi prediktif mampu menekan multiple dan reverberasi.

$$
\text { Power pada dekonvolusi spiking }
$$

memperlihatkan peningkatan power pada frekuensi tinggi yaitu memiliki nilai power noise dengan batas atas $-32 \mathrm{~dB}$. Nilai ini lebih tinggi dibandingkan pada dekonvolusi prediktif yang memiliki nilai power noise dengan batas atas $-50 \mathrm{~dB}$. Peningkatan power pada frekuensi tinggi yang dianggap noise pada dekonvolusi spiking membuktikan bahwa dekonvolusi spiking meningkatkan amplitudo noise berfrekuensi tinggi. Hal ini sesuai dengan Yilmaz (2001) yang menyatakan bahwa dekonvolusi spiking tidak selalu dapat diaplikasikan pada data lapang karena akan meningkatkan noise berfrekuensi tinggi pada data.

\section{Poststack time migration}

Penampang seismik hasil penerapan dekonvolusi spiking (Gambar 9) dan dekonvolusi prediktif (Gambar 10) membentuk pola reflektifitas struktur bawah permukaan yang ditamplikan dalam waktu tempuh gelombang TWT antara 3.200-4500 ms yang menunjukkan titik reflektor dengan variasi amplitudo untuk setiap reflektor secara vertikal. Gambar 8 merupakan penampang migrasi tanpa penerapan dekonvolusi. Lingkaran merah pada Gambar 8 menunjukkan ketidakstabilan yang terjadi saat akuisisi seismik di lapang sehingga menghasilkan beberapa refleksi yang muncul dan saling bertumpuk pada permukaan bawah laut. Selain itu refleksi bawah permukaan terlihat tidak kontinu dan waktu kemunculan refleksi menjadi berubah.

Gambar 10 merupakan penampang seismik dengan penerapan dekonvolusi prediktif. Dekonvolusi prediktif diterapkan padadata seismikuntukmenghilangkan noise yang bersifat periodik dalam domain waktu, yaitu multiple dan reverberasi. Pada Gambar 10 dasar laut dan multiple terlihat kuat dan kontinu. Namun setelah diperhatikan pada hasil migrasi, multiple muncul pada waktu 140-160 ms setelah water bottom sepanjang line FLRS-16. Multiple yang terlihat pada hasil migrasi tidak bersifat periodik yaitu prediktabilitasnya tidak konstan. Multiple ini tidak dapat dihilangkan secara keseluruhan dengan dekonvolusi. Hal ini disebabkan bentuk ekor signature yang tidak teratur akibat sinkronisasi array airgun di lapang yang kurang efektif.

Jika dibandingkan dengan penampang hasil dekonvolusi spiking terlihat bahwa hasil penampang seismik dengan dekonvolusi prediktif tidak memperlihatkan 
perbedaan yang signifikan. Keberadaan multiple pada Gambar 9 menunjukkan penerapan dekonvolusi spiking belum mampu untuk menekan multiple. Hal ini sesuai dengan teori bahwa dekonvolusi spiking diterapkan pada data seismik untuk mengembalikan bentuk wavelet dan tidak mampu untuk menekan multiple.

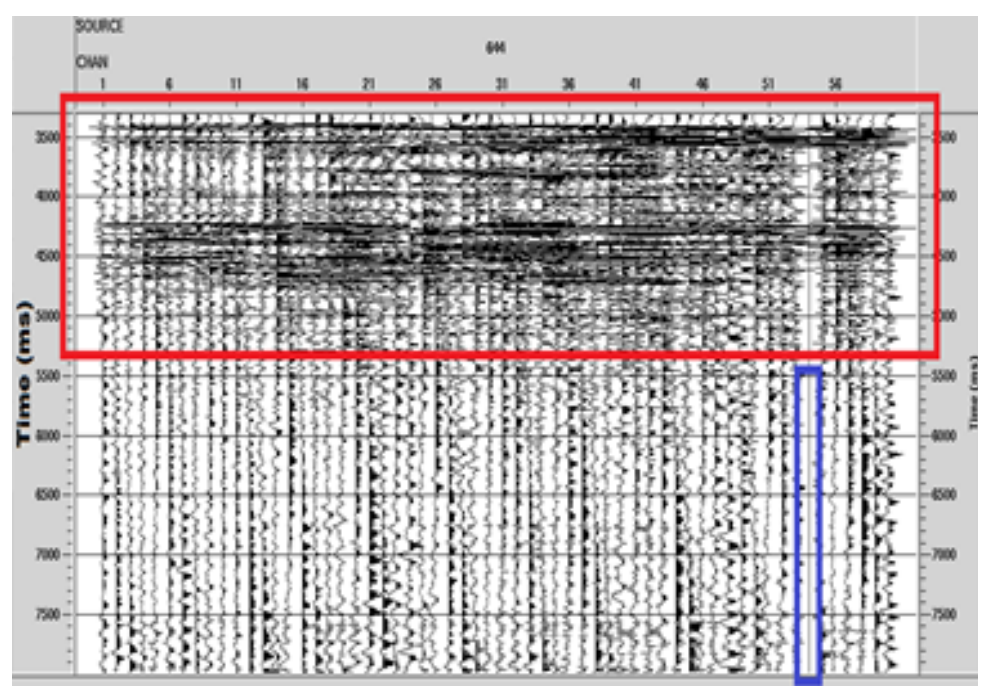

Gambar 3. Wiggle trace geometri, kotak merah menunjukkan campuran sinyal dan noise, kotak biru menunjukkan noise instrument

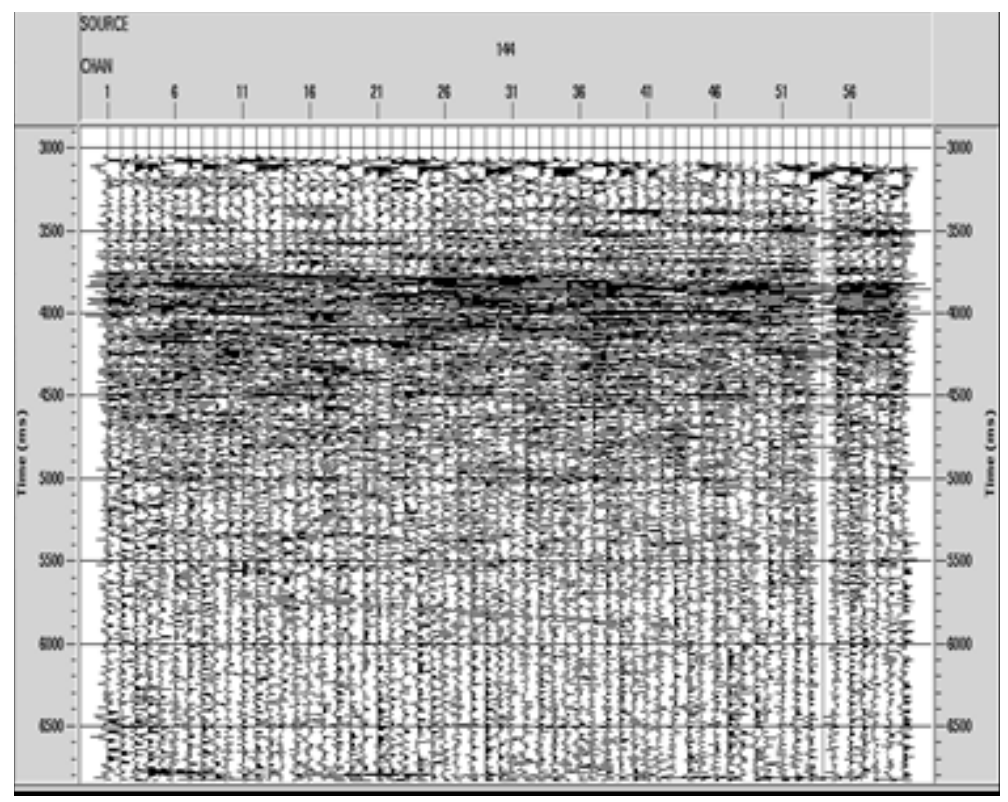

Gambar 4. Wiggle trace dekonvolusi spiking 


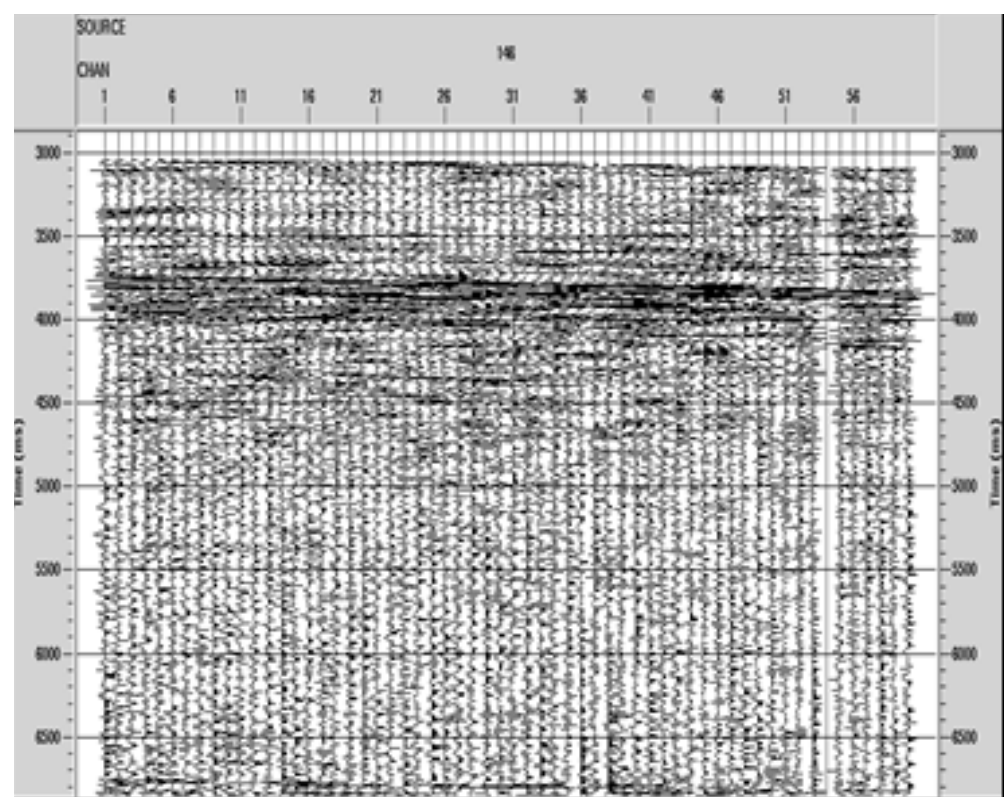

Gambar 5. Wiggle trace dekonvolusi prediktif

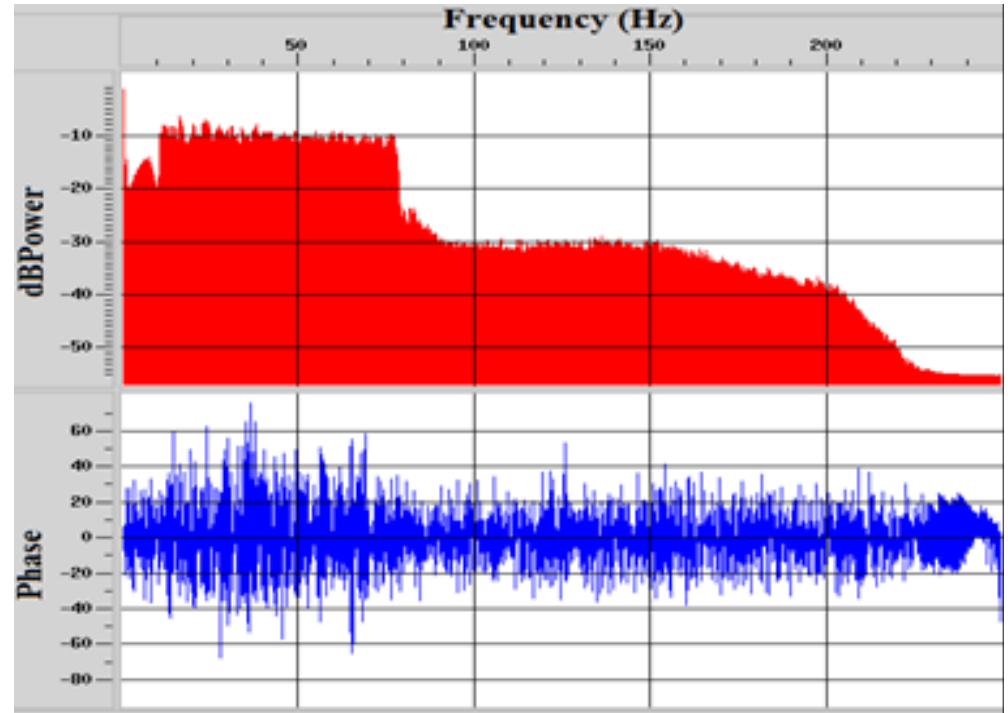

Gambar 6. Analisis spektral dekonvolusi spiking 


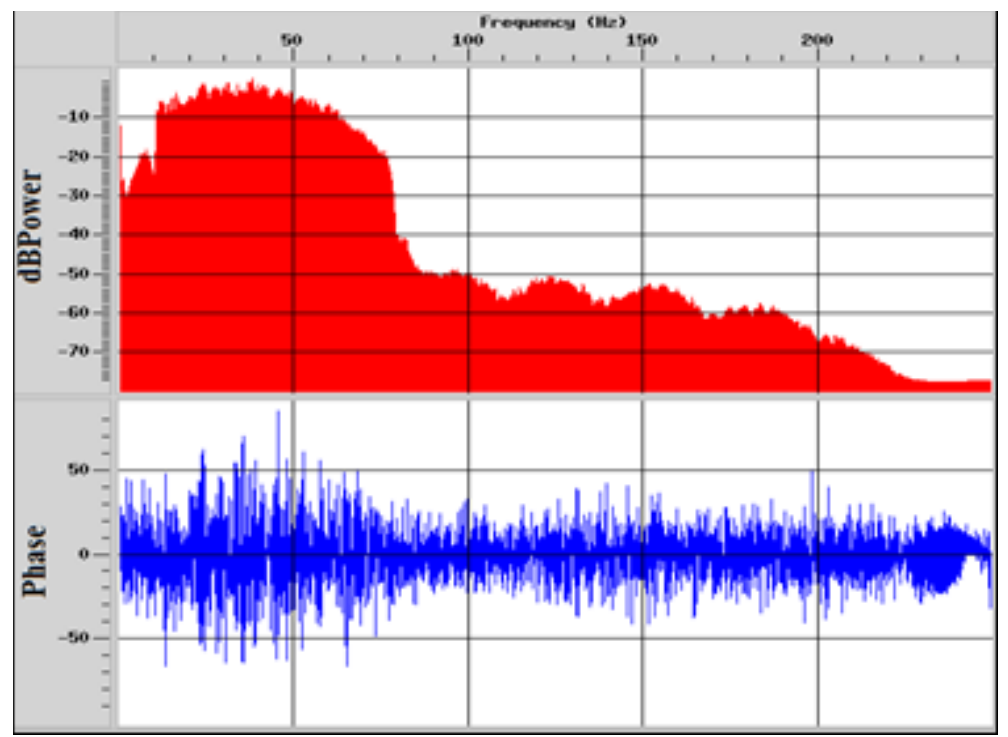

Gambar 7. Analisis spektral dekonvolusi prediktif

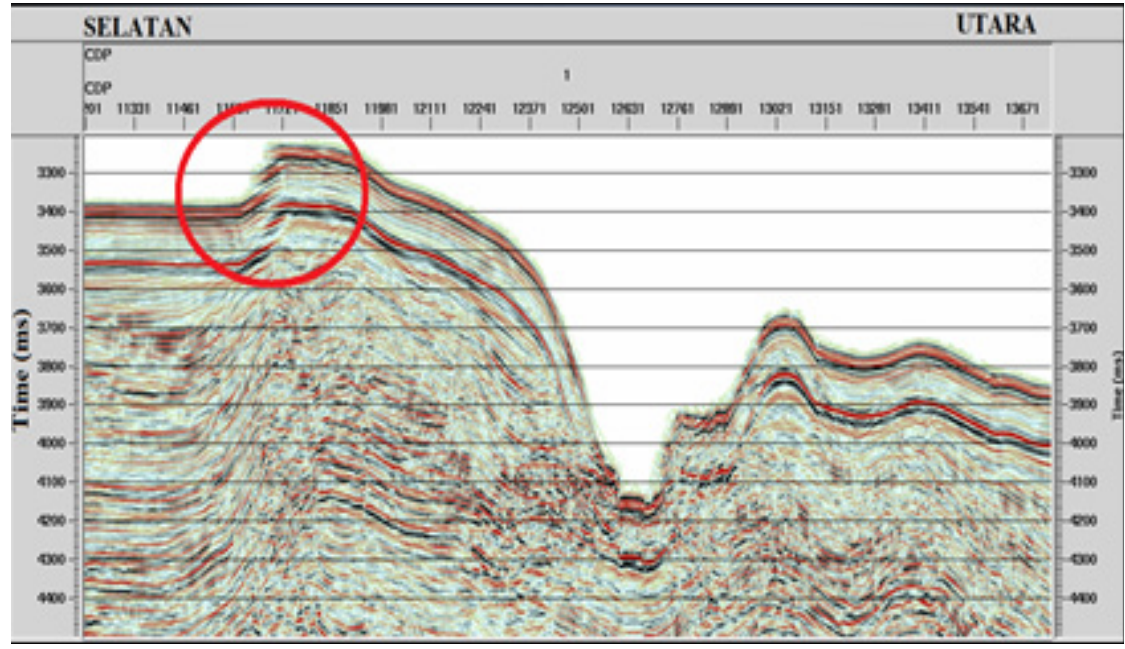

Gambar 8. Migrasi tanpa penerapan dekonvolusi, bingkai merah merupakan refleksi yang tidak kontinu

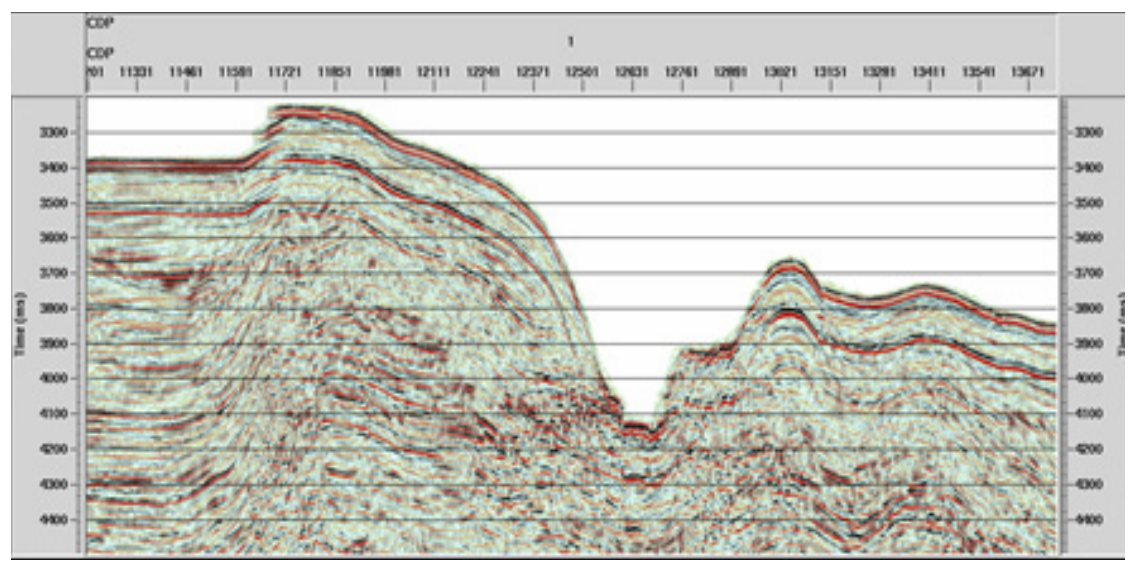

Gambar 9. Migrasi dengan penerapan dekonvolusi spiking, bingkai merah menunjukkan multiple pada penampang seismic 


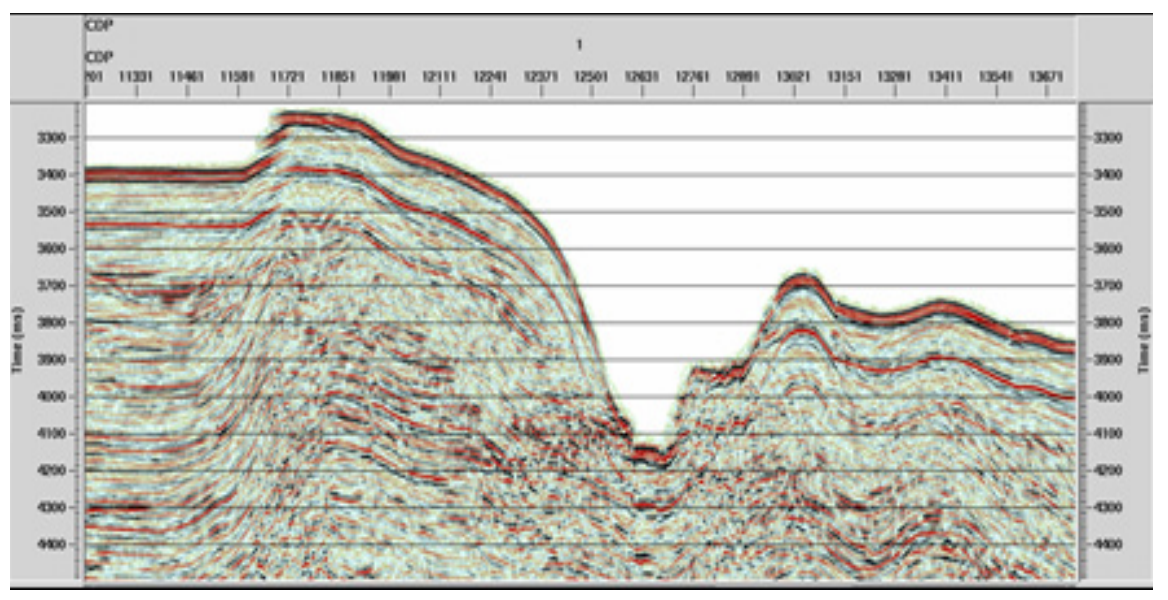

Gambar 10. Migrasi dengan penerapan dekonvolusi prediktif, bingkai merah menunjukkan multiple yang tidak teratenuasi dengan penerapan dekonvolusi prediktif

\section{KESIMPULAN DAN SARAN}

\section{Kesimpulan}

Hasil penerapan dekonvolusi pada data seismik laut Flores lintasan 16 memperlihatkan pada analisis spektral dekonvolusi prediktif lebih efektif untuk meningkatkan sinyal dan menekan noise dibandingkan dengan dekonvolusi spiking. Pada hasil penampang migrasi, dekonvolusi prediktif dan dekonvolusi spiking tidak memperlihatkan perbedaan yang signifikan. Dekonvolusi prediktif tidak mampu mengatenuasi multiple pada data seismik FLRS-16 karena dekonvolusi menjadi kurang efektif diterapkan pada data dengan ekor signature yang tidak teratur.

\section{Saran}

Penerapan dekonvolusi pada tahapan preprocessing (prestack deconvolution) belum dapat mengatenuasi multiple. Maka dari itu diperlukan penelitian lanjutan dengan menerapkan dekonvolusi pada tahapan processing yaitu deconvolution after stack (das) dan deconvolution after migration (dam). Selain itu dekonvolusi dapat diterapkan pada domain radon ( $\mathrm{\tau}-\mathrm{p})$ dan domain radial $(\mathrm{r}-\mathrm{t})$ untuk memisahkan noise dengan refleksi primer terlebih dahulu sehingga noise dapat lebih teratenuasi. Data sintetik dapat digunakan sebagai pembanding data lapang untuk menganalisa penerapan dekonvolusi secara teoritis.

\section{DAFTAR PUSTAKA}

Bestari SA. 2012. Penerapan metode dekonvolusi pada data seismik laut [Skripsi]. Bogor: Institut Pertanian Bogor.

Dey AK. 1999. An Analysis of seismic wavelet estimation [Thesis]. Alberta: University of Calgary

Dondurur D, Hakan K. 2012. Swell noise suppression by wiener prediction filter. Appl. Sci. Geo. 80:91-100.

Egbai JC, Atakpo E, Aigbogun CO. 2012. Predictive econvolution in seismic data processing in atala prospect of rivers state, Nigeria. Adv. Appl. Sci. Res. $3(1): 520-529$.

Ekasapta A. 2008. Wavelet seismik. http:// asyafe.wordpress.com/ [Diunduh : 1 Juni 2015].

Elboth T, Herrmansen. 2009. Attenuation in marine seismic data. SEG Techincal Program Extended Abstracts. 28(1):3312-3316.

Elboth T. 2010. Noise in marine seismic data. University of Oslo: Norway.

Harjumi M, Taufiq R. 2014. Analisis perbandingan parameter gap pada tahap dekonvolusi dalam pengolahan data seismik 2D darat. Prosiding Seminar Nasional Geofisika 2014. Makassar.

Kearey P, Michael B, Ian H. 2002. An introduction to geophysical exploration third edition. Blackwell Science Ltd. Oxford (UK).

Krail PM. 2010. Airguns: Theory and 
operation of the marine seismic source. University of Texas: Texas.

Lines L. 1996. Suppression of short-Period multiples-deconvolution or model based inversion?. Canadian Journal of Exploration Geophysics. 32(1):63-72.

Mukaddas A. 2005. Analisis perbedaan penampang seismik antara hasil pengolahan standar dengan pengolahan preserved amplitude. Mektek. 7(3):141-147.

Perez MA, David CH. 2000. Multiple attenuation via predictive deconvolution in the radial domain. the 12 th annual research report of the CREWES Project.

Peacock KL, Treitel S. 1969. Predictive deconvolution: theory and practice. Geophysics. 63:155-169.

Rahadian. 2011. Penerapan metode surface related multiple elimination dalam optimalisasi pengolahan data seismik 2D marine [Tesis]. Bandung: Institut Tekonologi Bandung.

Xiao C, John B, James B, Zhihong C. 2013. Multiple supression: a literature review. CREWES Research Report.

Yilmaz Ö. 1987. Seismic data processing. Tulsa (US). Society of Exploration Geophysics. Tulsa (US).

Yilmaz Ö. 2001. Seismic data analysis processing, inversion, and interpretation of seismic data volume 1. Society of Exploration Geophysics. Tulsa (US).

Zhu S, Bin W. 2013. Adaptive predictive deconvolution technique in marine seismic data processing. Advances in Information Service and Sciences. 5(10): 1041-1049. 